\title{
O perfil dos adolescentes que cumprem medida socioeducativa de prestação de serviços à comunidade em Maringá - PR
}

\author{
The profile of adolescents who abide by social provision of community services in \\ Maringá - Pr
}

\author{
José Lopes Silva * \\ Mabel Mascarenhas Torres ${ }^{* *}$
}

\begin{abstract}
Resumo:
Este artigo resulta da pesquisa sobre adolescentes em conflito com a lei e o cumprimento da medida sócio educativa de Prestação de Serviços a Comunidade no município de Maringá - PR. O objeto pesquisado identifica quem são os adolescentes que cumprem a medida socioeducativa de Prestação de Serviços a Comunidade, como vivem e quais os atos infracionais cometidos. Trata-se de uma pesquisa documental qualitativa, cujo objetivo foi o de construir uma breve reflexão sobre a infância e juventude para compreensão do envolvimento do adolescente em atos infracionais. A pesquisa foi realizada no Centro de Referência Sócio Educativo - CRSE, órgão executor das medidas sócio educativas de Prestação de Serviços a Comunidade e Liberdade Assistida, no município de Maringá- PR, ocorrendo em duas etapas: a revisão de literatura sobre os temas criança e adolescente em conflito com a lei, e a consulta ao banco de dados do CRSE. Os dados analisados foram: o registro dos prontuários dos adolescentes que cumprem a referida medida; os instrumentos utilizados pelos profissionais do CRSE nos atendimentos realizados. A coleta de dados foi desenvolvida no período de julho a novembro de 2010. Foi possível identificar o perfil do adolescente em cumprimento de medida sócio educativa de PSC no CRSE. Esta identificação nos deu a dimensão da situação econômica e social do adolescente e família atendidos pela equipe do programa.
\end{abstract}

Palavras-chave: Serviço social. Adolescente. Ato infracional. Medidas socioeducativas. Prestação de serviços à comunidade.

\begin{abstract}
:
This articles deals with the study of adolescents in conflict with the law, and as educational partner of the Community Service Render in Maringá-PR. The research was conducted at the Centre for Social and Educational Reference-CRSE, executing agency of social educative Service Delivery and the Community Assisted Freedom. We have conducted research in database and charts of sdolecents as well as tools
\end{abstract}

\footnotetext{
* Assistente Social formado pelo Centro Universitário de Maringá -CESUMAR; Especialização em Gestão de Socioeducação pela Universidade Estadual de Londrina - UEL lopesscrse@hotmail.com

** Assistente social, doutora em Serviço Social, professora da UEL. Coordenadora do grupo de pesquisa As expressões do exercício profissional desenvolvido pelos assistentes sociais. mmtorres@uel.br
} 
used by the Centre for Social Educational reference, in the period from July to November 2010. The research took place primarily through literature review that deals with the subject child and teenager, and drew up a brief background of the care of children and adolescents in Brazil. The second phase was done by consulting the database of the CRSE. This is a qualitative research, and aims to facilitate a brief reflection for the understanding of adolescent involvement in delinquency. Through the research, we were able to identify the profile of adolescents in accomplishment of social educative Service Render in the Community Partner Education Reference Center. This identification of the teen's profile has been possible by inquiring the database, records and instruments, which gave us the dimension of economic and social situation of adolescents and families served by the program staff.

Keywords: Social service. Adolescents. Breaking act. Measures educational partner. Provision of community services.

\section{Introdução}

Os anos de trabalho com adolescentes despertaram nosso interesse em buscar, na literatura, conhecimentos relacionados à prática vivenciada nas instituições, Abrigo Provisório Municipal e Centro de Referência Socioeducativo, e conhecer por meio da pesquisa social o perfil dos adolescentes autores de ato infracional que cumprem medida socioeducativa de Prestação de Serviços à Comunidade na cidade de Maringá-PR.

Para a construção deste artigo, além das obras dos autores: Arantes (2009), Faleiros (1995), Gonçalves (2002), Liberati (2010), Prates (2010), Rizzini (2008, 2009), Saraiva (2010), Soares $(2010)$ e Volpi $(2001,2008)$, que estudam e pesquisam sobre o tema criança e adolescente, buscamos entendimento nas determinações preconizadas na Constituição Federal do Brasil de 1988, e no Estatuto da Criança e do Adolescente - ECA (Lei Federal no 8,069/1990). A ênfase do estudo proposto neste artigo é o adolescente em conflito com a lei que cumpre medida socioeducativa de Prestação de Serviços à Comunidade.

Para alcançar os objetivos do trabalho proposto, realizamos uma pesquisa social, qualitativa documental, no CRSE - Centro de Referência Socioeeducativo, programa executor das medidas de Liberdade Assistida (LA) e Prestação de Serviços à Comunidade (PSC), na cidade de Maringá-PR. No CRSE, tivemos acesso às informações contidas no Banco de Dados do Programa; nos prontuários dos adolescentes, nos relatórios 
produzidos pelos técnicos e enviados à Vara da Infância e da Juventude da Comarca de Maringá-PR. Nosso objeto de pesquisa é conhecer quem são os adolescentes na faixa etária de 12 a 18 anos autores de ato infracional, que cumprem medida de Prestação de Serviços à Comunidade no ano de 2009.

Para obter as informações sobre os sujeitos da pesquisa, realizamos um levantamento sobre o número de adolescentes que cumpriram medida de PSC no ano 2009. Os dados dos adolescentes identificados foram: ano de nascimento, ato infracional praticado, escolaridade, cumprimento ou não da medida, se no decorrer do cumprimento da medida estavam ou não trabalhando, com quem e onde moram. Nesse primeiro levantamento, identificamos que no ano de 2009 passaram, pelo CRSE, 153 adolescentes do sexo masculino e 27 do sexo feminino, para o cumprimento de medida socioeducativa de PSC.

A partir desses dados, direcionamos nossa pesquisa aos prontuários. A escolha destes prontuários decorreu da identificação dos adolescentes, pois, é nesse instrumento que se encontram os registros mais detalhados acerca da trajetória do adolescente a partir do seu encaminhamento pelo sistema de justiça, para o CRSE.

Para que pudéssemos chegar a uma definição sobre quem são os adolescentes, analisamos os prontuários e selecionamos as informações que subsidiassem a construção de um perfil. Os resultados da pesquisa realizada foram apresentados em forma de tabelas, o que contribuiu para uma melhor visualização e interpretação das informações.

Para contemplar o objetivo proposto, procuramos analisar a questão que envolve a criança e o adolescente à luz de suas determinações históricas econômicas e sociais. Desse modo, subdividimos o trabalho em duas partes: na primeira parte, apresentamos (de forma breve) a contextualização da assistência à criança e ao adolescente no Brasil, fazendo um recorte a partir da segunda década do século $X X$, buscando embasamento teórico nas obras de autores que tratam do tema criança e adolescente. Discorremos ainda acerca da passagem do adolescente pelo Sistema de Justiça bem como sobre a legislação pertinente à área; na segunda parte, abordamos a implantação da medida socioeducativa de Prestação de Serviços à Comunidade (PSC) e Liberdade Assistida (LA) no município de Maringá. No ano de 2001, por meio da Lei municipal 2773/1990 que dispõe sobre a política municipal de atendimento dos direitos da criança e do adolescente 
e estabelece normas gerais para a sua adequada aplicação, ficaram estabelecidas as ações desenvolvidas pelo município no que se refere aos adolescentes em conflito com a lei (MARINGÁ, 1990).

\section{Assistência à infância no Brasil: herança cultural atrelada aos modelos econômicos}

Não é nossa pretensão pesquisar a história da criança e do adolescente no Brasil, mas, sim, buscar conhecimento nas obras literárias que tratam o tema, especialmente a partir da segunda década do século XX. Para tanto, recorremos a autores que discutem em suas obras a história da criança e do adolescente, entre os quais priorizamos Rizzini, $(2008,2009)$ Faleiros $(1995)$ e Volpi, $(2001,2008)$, autores estes que do nosso ponto de vista embasam teoricamente a construção do nosso trabalho. Além disso, consultamos material de vivência, na área da criança e adolescente, além de autores que tratam do tema adolescente em conflito com a lei, que cumprem a medida sócioeducativa de PSC, incluindo aí artigos disponíveis na internet. Analisamos também a legislação relativa à área da infância e juventude, a saber: o Código de Menores instituído sob o Decreto № 17, 943-A, de 12 de outubro de 1927; a Constituição Federal de 1988; O Estatuto da Criança e do Adolescente (ECA), lei № 8.069, de 13 de julho de 1990 e a Lei municipal no 2773 de 27 de novembro de 1990 de Maringá, que nortearam nosso trabalho.

Até as primeiras décadas do século $X X$, segundo a literatura consultada, o país contava com leis esparsas que tratavam da situação dos "menores", não contava com uma lei específica, voltada para a regulamentação da atenção à criança. Mas, desde o início da década de 1920, juristas, políticos e a sociedade empreenderiam incansável busca por instituir mecanismos capazes de definir a organização da assistência e proteção à infância no Brasil, dando origem ao primeiro Código de Menores, Decreto Lei № 17.943A de 1927, chamado de Código de Mello Mattos.

A primeira tentativa do governo em regulamentar a "assistência e proteção aos menores abandonados e delinqüentes", no início da década de 1920, legitimou a intervenção do Estado na família, não só através da suspensão do Pátrio Poder, mas também pela apreensão dos menores ditos abandonados, mesmo contra a vontade dos pais. Tal medida foi conseqüência da percepção que certos setores da sociedade tinham das famílias pobres (RIZZINI, 2009, p. 25). 
Fica claro neste período, década de 1920, a violenta intervenção do Estado sobre as famílias pobres, intervenção esta constituída pela ideologia dominante, cujo entendimento é de que as famílias pobres são incapazes de cuidar de seus filhos. "O Código de 1927 incorpora tanto a visão higienista de proteção do meio e do indivíduo, como a visão jurídica repressiva e moralista. Prevê a vigilância da saúde da criança, dos lactentes, das nutrizes e estabelece a inspeção médica de higiene." (FALEIROS, 1995, p. 63).

Esse modo de intervir reforça que o Estado delega poderes para que a autoridade pública fiscalize qualquer local onde se encontram crianças e adolescentes, cerceando até mesmo o direito de propriedade. Outro aspecto que merece destaque é a violação dos direitos das famílias, exemplificado na suspensão ou retirada do convívio familiar de crianças e adolescentes, caracterizando a perda do Pátrio Poder e exercendo, assim, domínio total sobre esses.

Mas, segundo Faleiros (1995), o Código de 1927 traz alguns avanços para a época, como, por exemplo, determinar a prisão especial para adolescente autor de ato infracional, e que a criança ou adolescente menor de 14 anos não mais seria submetido a processo penal. O Código estabelece a extinção da questão do discernimento, ${ }^{1}$ sob o qual eram estabelecidas as penas para crianças e adolescentes, em que a imputabilidade penal plena era fixada para os 14 anos de idade.

O Código de Menores de 1927, Decreto no 17.943-A, determina que aqueles que têm mais de 14 anos e menos de 18 serão submetidos a processo especial. Institui-se aí a Liberdade Vigiada, hoje Liberdade Assistida. A lei proíbe ainda o trabalho de crianças e adolescentes menores de 14 anos, mas, com a expansão da indústria, o código é modificado sob intervenção dos industriais, reduzindo a idade para 13 anos, e logo em seguida a Lei passou a permitir o trabalho a partir dos 12 anos.

Diante da necessidade de mão de obra no setor produtivo, e para atender aos interesses econômicos vigentes neste período histórico, o governo cria mecanismo de incentivo à família de prole numerosa, atribuindo um abono financeiro às famílias com mais de seis filhos, como meio de subsistência, e formação de mão de obra futura. Prevalece, aí, o jogo de poder sobre a família, cujo meio de sobrevivência era muitas

\footnotetext{
${ }^{1}$ Expresso no Código Penal dos Estados Unidos do Brasil, Decreto no 847, de 11 de outubro 1890.
} 
vezes o trabalho precário e mal remunerado, impondo às crianças e as adolescentes normas de conduta conforme o interesse do poder econômico.

Em 1941, o Estado inicia um novo modelo de atendimento para crianças e adolescentes. Nasce o Serviço de Assistência ao Menor - SAM, extinto na década de 1960. O SAM foi "[...] pensado para ser um grande pólo irradiador da nova racionalidade, acabou por ser conhecido, no final da década de 1950, como "famigerado" ou "escola do crime" (ARANTES, 2009, p. 191), criado para sistematizar e orientar os serviços de assistência social, dirigido aos "menores desvalidos" identificados na época. Este serviço foi extinto após passar por processo de investigação, cujos resultados foram considerados um escândalo nacional.

Na segunda metade da década de 1960, mais precisamente em 1964, militares assumem o poder a partir de um golpe de Estado, e passam a governar implantando profundas mudanças no Estado. "Designa o 'desaparecimento da política pela imposição da violência'. Substitui-se a política pela repressão, reina a tecnocracia enquanto a racionalização e organização da máquina administrativa em função de objetivos e metas fixadas de cima para baixo" (WEFFORT apud FALEIROS, 1995, p. 64).

Como agravante, o novo governo se depara com a crise da década de 1970 . O sistema capitalista busca novas formas de acumulação pautada no modelo econômico de globalização ${ }^{2}$ do capital, diminuindo drasticamente os postos de trabalho, pela troca de trabalho vivo por trabalho morto, com reflexo imediato nos países pobres, que sofrem com a diminuição de serviços básicos como saúde, educação, habitação entre outros, agravando ainda mais a situação de miséria das famílias pobres, com graves consequências para o segmento criança e adolescente.

Segundo Faleiros (1995), na área da criança e adolescente, essa nova forma de governo não foi diferente. Em 20 de novembro de 1964, o Congresso aprova a Lei № 4. 513, de 1/11/1964, que estabelece a Política Nacional do Bem-Estar do Menor, criando a FUNABEM - Fundação Nacional do Bem-Estar do Menor para executá-la. A FUNABEM tinha como propósito "assegurar" prioridade aos programas que visem à integração do

\footnotetext{
${ }^{2}$ Sobre globalização ver ALVES: 2001.
} 
menor $^{3}$ na comunidade, proporcionando assistência à própria família e aos lares substitutos, dar apoio às instituições que desenvolvessem trabalho voltado à família, e ainda respeitar as características de cada região. Porém, sob o domínio de um regime altamente centralizador, tais propósitos se dissiparam, prevalecendo a tecnocracia e o autoritarismo. Assim, "[...] a Entidade configurava-se como um meio de controle social, em nome da segurança nacional, cuja doutrina implica na "redução ou anulação das ameaças ou pressões antagônicas de qualquer origem." (FALEIROS, 1995, p. 65).

No final de 1970, é promulgado o Código de Menores (Lei no 6.697 de 1979), que na prática consagra o que vinha fazendo a FUNABEM. O novo Código traz de maneira expressiva a doutrina da Situação Irregular, ou seja,

Consagrava mediante o caráter tutelar da legislação a idéia de criminalização da pobreza. Seus destinatários foram as crianças e os jovens considerados em situação irregular, caracterizados como objeto potencial de intervenção do sistema de justiça, os Juizados de Menores, que não fazia qualquer distinção entre menor abandonado e delinqüente, pois na condição de menores em situação irregular enquadravam-se tanto os infratores quanto os menores abandonados (SOARES, 2010, p. 1).

Por conta da inexistência de uma proposta de trabalho capaz de distinguir as crianças que se encontravam em situação de abandono, e aquelas que realmente estavam em condição de autor da infração, era comum ocorrer prisões de crianças que só necessitavam de atendimento decorrentes de sua situação social.

Faleiros (1995) afirma que para a doutrina da situação irregular crianças e adolescentes não eram considerados sujeitos de direito quando se encontravam em estado de patologia social, ${ }^{4}$ ou seja, quando o atendimento às necessidades básicas das famílias era negado pelo Estado. O que se observava nesse período é que o Estado não apresentava nenhum programa de atendimento capaz de identificar a situação

\footnotetext{
${ }^{3}$ O termo 'menor', de larga utilização no senso comum, na imprensa e mesmo na pesquisa científica, tem uma origem pouco nobre. Cunhado no Brasil, pela medicina legal, e reconhecido pelo direito público para divisar a população entre responsáveis e irresponsáveis, segundo o critério do discernimento moral e do desenvolvimento psicológico, seu emprego generalizou-se para designar um tipo específico de criança, aquela procedente das classes populares, e, em situação de miséria absoluta, expulsa da escola desde a tenra idade, que faz da rua seu habitat e lugar privilegiado de reprodução cotidiana (GONÇALVES, 2002, p. 14).

${ }^{4}$ Patologia social pode, portanto, ser tratada por oposição à normalidade (PATOLOGIA SOCIAL, 2003).
} 
econômica da família, mas, esta era cobrada pelo Estado, reduzindo assim a ação dos pais ou do próprio "menor", fazendo-se da vítima um réu.

A \{Lei 6.697/1979\}, não passava de um código Penal do "Menor", disfarçado em sistema tutelar; suas medidas não passavam de verdadeiras sansões, ou seja, penas, disfarçadas em medidas de proteção. Não relacionava nem um direito, a não ser aquele sobre a assistência religiosa; não trazia nenhuma medida de apoio à família; tratava da situação irregular da criança e do jovem, que, na realidade, eram seres privados de seus direitos (LIBERATI, 2010, p. 15).

Já na década de 1980, segundo Arantes (2009), o modelo autoritário começa a perder força, a luta por um novo modelo econômico emerge por todos os cantos do país. Os direitos da crianças e dos adolescentes são postos em evidência por várias organizações. Destaca-se, nessa época, o Movimento Nacional dos Meninos e Meninas de Rua, a Pastoral do Menor e outras organizações não governamentais, tomando como base as discussões internacionais já em evidência. Ainda nessa década, desponta grande mobilização da sociedade brasileira, encabeçada pelos movimentos sociais e organizações não governamentais. Esta mobilização social buscava introduzir na Constituição Federal, a ser promulgada em 1988, os direitos da criança e do adolescente e, também, provar por meio de farta documentação a falência do modelo de atendimento dito "correcional e repressivo". Tais esforços não foram em vão, o capítulo VII da Constituição Federal de 1988, intitulado "Da Família, da Criança, do Adolescente e do Idoso", estabelece em seu art. 227 que:

\footnotetext{
É dever da família, da sociedade e do Estado assegurar à criança e ao adolescente, com absoluta prioridade, o direito à vida, à saúde, à alimentação, à educação, ao lazer, à profissionalização, à cultura, à dignidade, ao respeito, à liberdade e à convivência familiar e comunitária, além de colocá-los a salvo de toda a forma de negligência, discriminação, exploração, violência, crueldade e opressão (BRASIL, 2010).
}

Segundo Arantes (2009), na redação do art. 227 da Constituição Federal de 1988, o Brasil adotou não apenas a Declaração Universal dos Direitos da Criança e do Adolescente, como também o pretexto da convenção desses mesmos direitos, que, naquela data, ainda não havia sido apresentada à Assembléia Geral das Nações Unidas. 
Ao assim proceder, aboliu o Código de Menores de 1979 e, em seu lugar, em 1990 promulgou o Estatuto da Criança e do Adolescente, Lei no 8.069 de 13 de julho de 1990.

A aprovação do Estatuto da Criança e do Adolescente - ECA foi vista com entusiasmo por vários segmentos da sociedade brasileira. A criança passa a ser considerada sujeito de direitos, pelo princípio da absoluta prioridade no seu atendimento e pela observância de sua condição peculiar de pessoa em desenvolvimento.

Por Absoluta Prioridade entende-se que: na área administrativa, enquanto não existirem creches, escolas, postos de saúde, atendimento preventivo e emergencial às gestantes, dignas moradias e trabalho, não se deveriam asfaltar ruas, construírem praças, sambódromos, monumentos artísticos etc., porque a vida, a saúde, o lar, a prevenção de doenças são mais importantes que as obras de concreto que ficam para demonstrar o poder do governante (LIBERATI, 2010, p. 19)

Concordamos com o autor que é preciso administrar o público para o interesse público, e não construir obras para satisfazer os interesses particulares. Segundo Liberati (2010), o ECA, em seu art.5o, regulamenta a última parte do art.227 da Constituição Federal de 1988, cujo texto visa à proteção de todas as crianças e adolescentes da negligência, discriminação exploração, violência, crueldade, opressão e todos os atentados aos seus direitos quer por ação ou omissão.

O ECA estabelece as medidas protetivas em seu Artigo 98:

As medidas de proteção à criança e ao adolescente são aplicáveis sempre que os direitos reconhecidos nesta Lei forem ameaçados ou violados:

I - por ação ou omissão da sociedade ou do Estado;

II - por falta, omissão ou abuso dos pais ou responsável;

III - em razão de sua conduta (BRASIL, 1990).

Essas medidas alteram consideravelmente o modo como o atendimento dirigido a este segmento populacional é realizado. Com relação ao atendimento dirigido ao adolescente em conflito com a lei, o detalhamento ocorrerá no próximo item deste artigo.

\section{O adolescente autor de ato infracional e o sistema de justiça}

Neste item, abordaremos as medidas socioeducativas e o atendimento ao adolescente em conflito com a lei à luz das determinações do ECA. Para fins deste artigo, 
será dada ênfase à medida de PSC, tendo como parâmetro a literatura, buscando maior compreensão do perfil do adolescente autor de ato infracional.

A medida socioeducativa é ao mesmo tempo, a sansão e a oportunidade de ressocialização, contendo, portanto, uma dimensão coercitiva, uma vez que o adolescente é obrigado a cumpri-la, e educativa, uma vez que seu objetivo não se reduz a punir o adolescente, mas prepará-lo para o convívio social (VOLPI, 2001, p. 66)

O ECA, em seu artigo 103, considera ato infracional a conduta descrita como crime ou contravenção penal.

Quando o adolescente comete um ato infracional, é realizada pela autoridade policial ou por funcionário público (por obrigação), ou por cidadão (por opção) a apreensão. O adolescente é encaminhado à autoridade policial, que pode tanto realizar/proceder a liberação para entrega aos pais ou responsáveis, ou não. Quando não há a liberação, podem ocorrer três alternativas: apresentação direta ao Ministério Público, encaminhamento à repartição policial, em ambiente separado dos adultos, colocação em entidade de atendimento. Segundo o Artigo 112 do ECA:

\footnotetext{
Verificada a prática de ato infracional, a autoridade competente poderá aplicar ao adolescente as seguintes medidas:

I - advertência;

II - obrigação de reparar o dano;

III - prestação de serviços à comunidade;

IV - liberdade assistida;

$\mathrm{V}$ - inserção em regime de semi-liberdade;

VI - internação em estabelecimento educacional;

VII - qualquer uma das previstas no art. 101, I a VI (BRASIL, 1990).
}

O Ministério Público (MP) é responsável pela remissão (extinção) pelo arquivamento e também pelo encaminhamento para o Programa executor das medidas socioeducativas. Concordamos com Saraiva (2010) que uma boa rede de atendimento, um bem estruturado programa de Prestação de Serviços à Comunidade, é capaz de prevenir a internação. Há falha grave no sistema de atendimento em meio aberto e a consequência imediata disto é o inchaço do sistema de privação de liberdade. A Prestação de Serviços à Comunidade, conforme o artigo 117, do ECA, "consiste na realização de tarefas gratuitas de interesse geral, por período não excedente a 06 meses, 
junto a entidades assistências, hospitais, escolas e outros estabelecimentos congêneres, bem como em programas comunitários ou governamentais" (BRASIL, 1990).

Como nem todo ato infracional é motivador de privação de liberdade, a medida em meio aberto de Prestação de Serviços à Comunidade prima pelo caráter educativo na sua intervenção. Desse modo, as tarefas a serem atribuídas ao adolescente devem levar em conta o aspecto formativo, aptidões e preferências para que a reflexão sobre seu ato, sua trajetória pessoal e social possa acontecer.

A medida, assim cumprida, objetiva ao adolescente a possibilidade de se reconhecer e rever sua conduta, a percepção de seu papel social, a identificação de passos para a não reincidência de fatos semelhantes, o seu relacionamento com a sociedade dos adultos e condução ética na relação e no processo de cumprimento da medida.

Quanto às tarefas que poderão ser executadas pelos adolescentes, estas decorrem do estabelecido no artigo 117 parágrafo único do ECA: “jornada máxima de 08 horas semanais, aos sábados, domingos e feriados ou em dias úteis, de modo a não prejudicar a freqüência escolar ou jornada normal de trabalho". Essas determinações do ECA devem ser intercaladas com o atendimento sistematizado pela equipe. É nesse momento que os profissionais procuram se inteirar das demandas recorrentes da condição de vida do adolescente e de sua família.

Com base na fundamentação teórica encontrada na bibliografia estudada, nas práticas e trabalhos desenvolvidos junto aos adolescentes em conflito com a lei, identificamos a necessidade do fortalecimento dos Programas em Meio Aberto, incluindo aí maior investimento em recursos humanos, por meio da capacitação profissional permanente e até mesmo da participação de técnicos como parte das equipes especializadas para a Prestação de Serviços a Comunidade - PSC. A nosso ver, a importância do Meio Aberto requer, ainda, estudos mais aprofundados sobre a limitação da medida de PSC como instrumento de aproximação do adolescente com a sociedade, sendo destinada apenas àqueles que cometem ato infracional. A Prestação de Serviços à Comunidade é uma medida que oportuniza ao adolescente a formação de valores e atitudes construtivas, e dá à sociedade oportunidade de se organizar para colaborar na preparação do adolescente para o convívio social. 
O ECA, em seu art. 117 - Parágrafo único, é claro quando determina que: “[...] as tarefas serão atribuídas conforme as aptidões do adolescente [...]" (BRASIL, 1990), respeitando-o como pessoa em fase peculiar de desenvolvimento. Portanto, é necessário o envolvimento da família nos serviços e bens sociais comunitários, como também a participação da rede social, e da sociedade como um todo, possibilitando ao adolescente a oportunidade de construir, com apoio dos envolvidos, um espaço para si mesmo na sociedade.

Tal procedimento pode trazer ao adolescente o reconhecimento de sua conduta indevida e a convicção de seu próprio valor como ser humano. Volpi $(2008$, p. 168) referese à Prestação de Serviços à Comunidade como uma forma de o adolescente "[...] demonstrar a si próprio e a sociedade que são capazes de atos construtivos e reparadores $[\ldots]^{\prime \prime}$.

Para a construção deste artigo, além das obras literárias de autores que tratam do tema, as determinações preconizadas na Constituição Federal de 1988, e no ECA, foi realizada uma pesquisa documental, de abordagem qualitativa junto ao Centro de Referência Socioeducativo - CRSE, localizado a Avenida Centenário, no 495, Zona 08, Maringá - PR. O objetivo deste Centro é atender adolescentes na faixa etária de 12 a 18 anos de idade, autores de ato infracional com determinação de cumprimento de medida socioeducativa de Prestação de Serviços à Comunidade e Liberdade Assistida encaminhados pela Vara da Infância e da Juventude do município de Maringá-PR.

O CRSE foi criado em 2001, iniciando suas atividades no mesmo ano. Tendo em vista o número de adolescentes atendidos, e o volume de informações pesquisadas, limitamos nossa pesquisa apenas ao ano de 2009. Trata-se de uma pesquisa documental, acessando o banco de dados do CRSE, o registro dos prontuários dos adolescentes que cumprem a referida medida, bem como os instrumentos utilizados pelos profissionais do CRSE nos atendimentos realizados.

\section{A prestação de serviços à comunidade no município de Maringá}

Mesmo ante a promulgação do Estatuto da Criança e do Adolescente Lei no 8069, de 13 julho de 1990 e da Lei 2773/90, que dispõe sobre a Política Municipal de Atendimento e Defesa dos Direitos da Criança e do Adolescente, os Programas de 
atendimento a crianças e adolescentes existentes na época não contemplavam as medidas de Liberdade Assistida e de Prestação de Serviços à Comunidade no município de Maringá.

Em 2001 é realizada em Maringá-PR a proposta Técnica de Implantação das Medidas Socioeducativas em meio aberto (Prestação de Serviços à Comunidade, art.117 e Liberdade Assistida, art.118 do ECA), com a finalidade de apresentar o debate acerca da questão do adolescente em conflito com a lei no município, e tendo em vista a diretriz de municipalização e regionalização da atenção ao adolescente, em conformidade com a doutrina de Proteção Integral. A proposta de implantação baseava-se na compreensão do direito do adolescente autor de ato infracional (em conflito com a lei) cumprir medida socioeducativa, cumulativa ou não com outras medidas de proteção, visando o rigor de seu estabelecimento pela Lei federal no. 8,069/90 e pelas demais recomendações internacionais. $^{5}$

O rol de medidas socioeducativas estabelecidas pelo ECA tem competências e responsabilidades diferenciadas em seu trato e acompanhamento, algumas delas não se justificam enquanto programas socioeducativos por iniciar-se sua ação e finalizar-se no próprio sistema de justiça (Poder Judiciário e Ministério Público) como a advertência e a obrigação de reparação de danos. As demais, como a Liberdade Assistida, Prestação de Serviços à Comunidade, Semiliberdade, Internação Provisória e Privação de Liberdade, compõem programas sociais, tendo em vista a definição de tempo mínimo e máximo para seu cumprimento, princípios e diretrizes claras para sua implementação e acompanhamento, responsabilidade e metodologias de ação específica.

A proposta técnica, produzida pela equipe da Secretaria de Ação Social e Cidadania de Maringá, sobre a implantação das medidas socioeducativas em Maringá, foi aprovada em 2001, iniciando suas atividades práticas no mesmo ano, tendo como órgão executor o Centro de Referência Sócio Educativo (CRSE), entidade inserida dentro da Política de Proteção Social Especial, cuja função é realizar o atendimento e encaminhamento de

\footnotetext{
${ }^{5}$ Declaração de Genebra (1924), Declaração Universal dos Direitos Humanos das Nações Unidas (1948), Convenção Americana sobre Direitos Humanos/Pacto de São José (1969), Regras mínimas de Beijing (1985), Diretrizes nas Nações Unidas para a proteção dos jovens privados de liberdade (1990), resoluções/convenções últimas que lançaram as bases para a formulação de um novo ordenamento no campo do direito e da justiça, possível para todos os países, em quaisquer condição que se encontre, cuja característica fundamental é a dignidade da criança.
} 
adolescentes em conflito com a lei, na faixa etária de 12 a 18 anos em cumprimento de medidas socioeducativas de Liberdade Assistida e Prestação de Serviços à Comunidade, como rege o ECA.

Tais medidas são aplicadas aos adolescentes autores de atos infracionais por meio do Juízo e Ministério Público da Vara da Infância e Juventude da Comarca de Maringá, que posteriormente encaminham os adolescentes ao CRSE para a efetivação e o cumprimento das medidas aplicadas. Em nossa pesquisa, enfatizamos a medida de PSC, que conta com instrumentos facilitadores para a execução do trabalho.

Os instrumentos utilizados no atendimento ao adolescente são:

- Formulário para entrevista: este instrumento contém os dados pessoais do adolescente, escolaridade, ato infracional e uso de substância psicoativa, renda da família, moradia e composição familiar;

- Ficha para encaminhamento: tem como função realizar o encaminhamento do adolescente para instituição conveniada. Contém o nome e o endereço da instituição, nome e idade do adolescente, no do ofício, prazo da medida;

- Folha ponto: contém o nome e endereço da Instituição, nome e idade do adolescente prazo da medida, mês e ano, além da tabela para acompanhamento dos horários de trabalho, assinatura do adolescente e do responsável pelo monitoramento. É por meio deste instrumento que se confirma o cumprimento da medida e se executa o encerramento do processo jurídico do adolescente;

- Ficha de inscrição: para o Programa Adolescente Aprendiz (Programa estadual específico para o adolescente em conflito com Lei), contém dados pessoais do adolescente, endereço, telefone, situação escolar, e resumo do ato infracional.

Para obter as informações sobre os sujeitos da pesquisa, adolescentes que se encontravam em conflito com a lei e cumprindo medida socioeducativa de Prestação de Serviços à Comunidade no CRSE no ano de 2009, realizamos, em primeiro lugar, um levantamento sobre a quantidade de adolescentes em cumprimento de medida na época. Esses adolescentes foram identificados por sexo, ano de nascimento, ato infracional, escolaridade, condições de trabalho e moradia. As informações foram coletadas por meio dos documentos acima citados, relatórios enviados a Vara da Infância, prontuários e convocações enviadas às residências dos adolescentes. 
Para análise dos dados, selecionamos as seguintes informações: ato Infracional, condições de trabalho e moradia. Sobre o ato infracional observados as informações referentes ao tipo de delito: tráfico, briga, roubo/furto, DSH (dirigir sem habilitação) e outros. Com relação à informação condições de trabalho, foram identificados adolescentes que estão trabalhando e adolescentes que estão fora do mercado de trabalho. Esta variável foi analisada também relacionada à renda da família. Quanto à escolaridade, foram consideradas as seguintes variáveis: escolaridade de 1 a a 8a série do ensino fundamental, e do 1 을 ao 3 o ano do ensino médio. Sobre a questão da moradia, destacamos com quem e aonde o adolescente mora. Foram consideradas as variáveis: mora com o pai e mãe, só com a mãe, só com o pai, com os avós e outros. Onde moram, foram consideradas as regiões: centro, zona norte e zona sul da cidade.

O processo de escolha de cada variável foi possível, levando-se em consideração a maior demanda constatada na pesquisa. Os dados coletados foram apresentados em forma de quadros e tabelas de modo a facilitar o acesso às informações.

\section{Dados de identificação dos adolescentes}

Em um primeiro levantamento identificamos 153 adolescentes do sexo masculino e 27 do sexo feminino. Com esses dados, direcionamos nossa pesquisa à consulta aos prontuários e instrumentos, nos quais se encontravam os registros mais detalhados da trajetória dos adolescentes a partir do seu encaminhamento pelo sistema de justiça para o CRSE.

Tabela 1 - Distribuição dos adolescentes por ano de nascimento e escolaridade e situação de trabalho (feminino)

\begin{tabular}{|c|c|c|c|c|c|c|c|c|c|c|c|c|}
\hline & \multicolumn{2}{|c|}{$1^{\circ} a 4^{\circ}-E . F$} & \multicolumn{2}{|c|}{$\begin{array}{c}\text { 5o a8o- } \\
\text { E. } F\end{array}$} & \multicolumn{2}{|c|}{ 1ㅇ-E. M } & \multicolumn{2}{|c|}{ 2o-E. M } & \multicolumn{2}{|c|}{ 3ㅇ--E. M } & \multicolumn{2}{|c|}{ Total } \\
\hline & T.B & N.T & T.B & N.T & T.B & N.T & T.B & N.T & T.B & N.T & T.B & N.T \\
\hline 1991 & - & - & - & 02 & 01 & - & - & 01 & - & 01 & 01 & 04 \\
\hline 1992 & - & - & - & 01 & 02 & 02 & - & 02 & - & - & 02 & 05 \\
\hline 1993 & - & 01 & - & 01 & - & 01 & - & - & - & - & - & 03 \\
\hline 1994 & - & - & 01 & 04 & - & 01 & - & - & - & - & 01 & 05 \\
\hline 1995 & - & - & - & 05 & - & - & - & - & - & - & - & 05 \\
\hline 1997 & - & - & - & 01 & - & - & - & - & - & - & - & 01 \\
\hline Total & - & 01 & 01 & 14 & 03 & 04 & - & 03 & - & 01 & 04 & 23 \\
\hline
\end{tabular}

*T.B- trabalha / N.T - não trabalha - E.F-Ensino fundamental / E.M-Ensino médio - Pesquisa realizada no período de jul. a nov. de 2010 no CRSE. 
Fonte: os autores a partir do registro dos profissionais do CRSE: pesquisa realizada no período de jul. a nov. de 2010 no CRSE.

No que se refere à escolaridade, as adolescentes do sexo feminino que cometeram ato infracional cursavam, na época, o ensino fundamental, correspondendo um total de $56 \%$. Nota-se, na comparação com a idade, a defasagem escolar. Com relação à inclusão no mercado de trabalho, 15\% delas, com idade de 17 anos, estavam no mercado.

Tabela 2 - Distribuição dos adolescentes por ano de nascimento e escolaridade e situação de trabalho (masculino)

\begin{tabular}{c|cc|cc|cc|cc|cc|cc}
\hline & \multicolumn{2}{|c|}{$1^{\circ} a 4^{\circ}-E . F$} & \multicolumn{2}{c|}{ 5o $a 8$ o- $E}$. & \multicolumn{2}{c|}{ 1ㅇ-E. $M$} & \multicolumn{2}{c|}{ 2o-E. $M$} & 3o-E. $M$ & \multicolumn{2}{c}{ Total } \\
& & & \multicolumn{2}{|c|}{$F$} & & & & & & & \\
\hline & TB & NT & TB & NT & TB & NT & TB & NT & TB & NT & TB & NT \\
1991 & - & 01 & 13 & 19 & 05 & 02 & 02 & 01 & 02 & 01 & 22 & 24 \\
1992 & - & - & 13 & 18 & 03 & 01 & - & 03 & 02 & 01 & 18 & 23 \\
1993 & - & - & 06 & 24 & 01 & 05 & - & 01 & - & - & 07 & 30 \\
1994 & - & 02 & 02 & 11 & - & 03 & - & - & - & - & 02 & 16 \\
1995 & - & 01 & - & 07 & - & - & - & - & - & - & - & 08 \\
1996 & - & - & - & 03 & - & - & - & - & - & - & - & 03 \\
\hline Total & - & 04 & 34 & 82 & 09 & 11 & 02 & 05 & 04 & 02 & 49 & 104 \\
\hline
\end{tabular}

*T.B- trabalha / N.T - não trabalha - E.F-Ensino fundamental / E.M-Ensino médio - Pesquisa realizada no período de jul. a nov. de 2010 no CRSE.

Fonte: os autores a partir do registro dos profissionais do CRSE: pesquisa realizada no período de jul. a nov. de 2010 no CRSE.

No que se refere à escolaridade, o maior número de adolescentes do sexo masculino se encontrava cursando o ensino fundamental, chegando a $76 \%$ do total pesquisado, oscilando entre os 16 e 17 anos de idade. Nota-se, na comparação com a idade, a defasagem escolar. Com relação à inclusão no mercado de trabalho, $22 \%$ estavam trabalhando na época, com idade correspondente entre 16 e 17 anos.

Tabela 3 - Distribuição dos adolescentes por ano de nascimento, região de moradia e com quem mora (Feminino)

\begin{tabular}{|c|c|c|c|c|c|c|c|c|c|c|c|c|c|c|c|c|c|c|}
\hline & \multicolumn{3}{|c|}{ Pai e mãe } & \multicolumn{3}{|c|}{ Mãe } & \multicolumn{3}{|c|}{ Pai } & \multicolumn{3}{|c|}{ Avós } & \multicolumn{3}{|c|}{ Outros } & \multicolumn{3}{|c|}{ Total } \\
\hline & $\mathrm{CE}$ & $\mathrm{ZN}$ & ZS & CE & $\mathrm{ZN}$ & ZS & CE & $\mathrm{ZN}$ & ZS & CE & $\mathrm{ZN}$ & ZS & CE & ZN & ZS & CE & $\mathrm{ZN}$ & ZS \\
\hline 1991 & 01 & 03 & - & 01 & - & - & - & - & - & - & - & - & - & - & - & 02 & 03 & - \\
\hline 1992 & 01 & 02 & - & - & 01 & 01 & - & - & - & - & - & - & - & 01 & - & 01 & 04 & 01 \\
\hline 1993 & - & - & 01 & - & 01 & - & - & 01 & - & - & - & - & - & - & - & - & 02 & 01 \\
\hline 1994 & 01 & - & - & - & 01 & 03 & - & - & 01 & - & - & - & - & - & - & 01 & 01 & 04 \\
\hline 1995 & - & 02 & - & - & 04 & - & - & - & - & - & - & - & - & - & - & - & 06 & - \\
\hline 1997 & - & - & - & - & 01 & - & - & - & - & - & - & - & - & - & - & - & 01 & - \\
\hline Total & 03 & 07 & 01 & 01 & 08 & 04 & - & 01 & 01 & - & - & - & - & 01 & - & 04 & 17 & 06 \\
\hline
\end{tabular}

*C.E-Centro / Z.N-Zona Norte / Z.S-Zona sul - Pesquisa realizada no período de jul. a nov. de 2010 no CRSE.

Fonte: os autores a partir do registro dos profissionais do CRSE: pesquisa realizada no período de jul. a nov. de 2010 no CRSE. 
Sobre a variável com quem mora, entre as adolescentes do sexo feminino $51 \%$ mora com a mãe. Neste item, identificamos (dados dos prontuários) que muitas mães são as únicas responsáveis pela subsistência da família, o pai afastou-se do convívio familiar, constituindo outra família, não assumindo compromissos legais como pensão alimentícia.

Em relação à região que mora, 63\% reside na zona norte da cidade. Os prontuários pesquisados indicam que a maioria cometeu ato infracional aos 14 anos de idade.

Tabela 4 - Distribuição dos adolescentes por ano de nascimento, região de moradia e com quem mora (masculino)

\begin{tabular}{|c|c|c|c|c|c|c|c|c|c|c|c|c|c|c|c|c|c|c|}
\hline & \multicolumn{3}{|c|}{ Pai e mãe } & \multicolumn{3}{|c|}{ Mãe } & \multicolumn{3}{|c|}{ Pai } & \multicolumn{3}{|c|}{ Avós } & \multicolumn{3}{|c|}{ Outros } & \multicolumn{3}{|c|}{ Total } \\
\hline & $\mathrm{CE}$ & $Z \mathrm{ZN}$ & ZS & CE & ZN & ZS & $\mathrm{CE}$ & ZN & ZS & CE & ZN & ZS & $\mathrm{CE}$ & $\mathrm{ZN}$ & ZS & CE & $\mathrm{ZN}$ & ZS \\
\hline 1991 & 03 & 18 & 05 & 02 & 06 & 05 & - & 03 & 01 & - & - & - & 01 & 01 & 02 & 06 & 28 & 13 \\
\hline 1992 & 05 & 19 & 01 & 02 & 05 & 03 & - & 01 & 01 & - & 01 & 01 & - & 01 & 01 & 07 & 27 & 07 \\
\hline 1993 & - & 16 & 03 & - & 10 & 05 & - & 01 & - & - & - & - & - & 01 & - & - & 28 & 08 \\
\hline 1994 & 01 & 03 & 02 & - & 09 & - & 01 & - & - & - & 02 & - & - & - & - & 02 & 14 & 02 \\
\hline 1995 & - & 03 & 03 & - & 01 & - & - & - & - & - & - & - & - & - & 01 & - & 04 & 04 \\
\hline 1996 & 01 & - & - & - & - & 02 & - & - & - & - & - & - & - & - & - & 01 & - & 02 \\
\hline Total & 10 & 59 & 14 & 04 & 31 & 15 & 01 & 05 & 02 & - & 03 & 01 & 01 & 03 & 04 & 16 & 101 & 36 \\
\hline
\end{tabular}

*C.E-Centro / Z.N-Zona Norte / Z.S-Zona sul - Pesquisa realizada no período de jul. a nov. de 2010 no CRSE. Fonte: os autores a partir do registro dos profissionais do CRSE: pesquisa realizada no período de jul. a nov. de 2010 no CRSE.

Com relação à moradia entre os adolescentes do sexo masculino, o item reside com os pais superou os outros itens pesquisados, ou seja, mais de $53 \%$ dos adolescentes residiam com a família nuclear. Com relação aos demais, identificamos um número significativo de adolescentes que residem somente com a mãe, a saber, 50 adolescentes.

Quanto à região de moradia, $67 \%$ dos pesquisados moram na zona norte, com faixa etária entre os 15 e 17 anos idade.

Para ter uma posição geográfica do local onde moram os adolescentes que tiveram passagem pelo CRSE no ano de 2009, procuramos fazer o mapeamento da cidade dividindo-a em três regiões, CENTRO, ZONA SUL e ZONA NORTE. Esta divisão ocorreu sob a orientação do órgão responsável pela demarcação geográfica do município. É importante observar que a constituição dos bairros, jardins e zonas que compuseram tais regiões foi registrada de acordo com os resultados obtidos por meio da pesquisa, que detectou a existência de adolescentes autores de ato infracional, e com medida de Prestação de Serviços à Comunidade, em cada região. 
Pelo que foi constatado por meio da pesquisa, a região que apresentou maior vulnerabilidade social é a zona norte, onde se localizam os bairros Conjunto Requião e Jardim Alvorada. O Conjunto Santa Felicidade pode ser considerado como exceção pois está localizado na zona sul da cidade.

Quadro 1 - Distribuição dos Bairros de moradia dos adolescentes por região/zona

\begin{tabular}{|l|l|}
\hline \multicolumn{1}{|c|}{ Região/Zona } & \multicolumn{1}{c|}{ Bairros } \\
\hline Região Centro & Zona 02, Zona 04, Zona 05, Zona 06, e Zona 07 \\
\hline Zona Sul & $\begin{array}{l}\text { Vila Operária, Jardim Aclimação, Jardim Novo Horizonte, Jardim São Silvestre, Conjunto } \\
\text { Cidade Canção, Cidade Alta, Vila Nova, Jardim Paraíso, Santa Felicidade, Jardim Botânico, } \\
\text { Jardim Bertioga, Itaipu, Jardim Prolar, Jardim Universo, Jardim Tarumã, Jardim Madri, } \\
\text { Jardim Ipanema, Vila Bosque, Sanenge, Cidade Alta I, Borba Gato, Ipanema, e o Distrito } \\
\text { de Floriano }\end{array}$ \\
\hline Zona Norte & $\begin{array}{l}\text { Jardim Batel, Conjunto Guaiapó, Jardim Alvorada, Vila Morangueira, Conjunto Requião, } \\
\text { Parque das Laranjeiras, Parque das Palmeiras, Jardim Quebec, Jardim Montreal, Jardim } \\
\text { Olímpico, Jardim Copacabana, Vila Esperança, Jardim Ebenezer, Jardim Grajaú, Conjunto } \\
\text { Thaís, Jardim Mandacaru, Jardim Patrícia, Jardim América, Conjunto Ney Braga, Conjunto } \\
\text { Itaparica, Jardim São Francisco, Parque das Bandeiras, jardim São Jorge, Jardim Glória, } \\
\text { Jardim Santa Helena, Parque Avenida, Jardim Liberdade, Jardim Canadá, vila } \\
\text { Morangueirinha, Imperial II, Parque Hortência, Parque das Grevilhas, Vila Santa Isabel, } \\
\text { Jardim dos Pássaros, Conjunto Chapangna, Vila Morumbi, Conjunto Hermes Morais de } \\
\text { Barros, Vila Emília, Portal das Torres, Conjunto Itatiaia, Conjunto branca Vieira, Conjunto } \\
\text { Lea Leal, Jardim Diamante, Jardim Diamante, Jardim Piatã, Grevilhas II, Jardim Vitória, } \\
\text { Jardim Kakogawa, Jardim Atlanta, Jardim Copacabana e Distrito de Iguatemi }\end{array}$ \\
\hline
\end{tabular}

Fonte: os autores a partir do registro dos profissionais do CRSE: pesquisa realizada no período de jul. a nov. de 2010 no CRSE.

A partir destes dados, identificamos que $11 \%$ dos adolescentes que cumpriram medida em 2009 residiam na região central da cidade. Na região sul, 22.7\%, e 66.3\% dos adolescentes residiam na Zona Norte. Do total dos prontuários pesquisados, 8.8\% mora no Conjunto Requião, seguido por $8.3 \%$ que são moradores do Jardim Alvorada.

\section{A renda familiar}

Os dados pesquisados mostram uma realidade em relação às famílias de adolescentes que cometem ato infracional. Entre os prontuários consultados, 17,2\% das famílias informaram, na época, manter uma renda mensal acima de três salários mínimos. Identificamos, por meio dos dados, que mais da metade das famílias vivem em situação de pobreza, ou seja, 52,5\% declararam ter renda familiar de um a três salários mínimos. ${ }^{6}$ Dos 180 prontuários pesquisados, 30,3\% eram de adolescentes cujas famílias sobreviviam

${ }^{6} \mathrm{R} \$ 465,00$ (quatrocentos e sessenta e cinco reais) era o valor do salário mínimo em 2009. 
com renda de até um salário mínimo, ou seja, são famílias que estão vivendo dentro da linha de extrema pobreza.

\section{O cumprimento da medida}

Neste item, as adolescentes do sexo feminino tiveram aproveitamento superior aos adolescentes do sexo masculino. Das adolescentes pesquisadas apenas 3,7\% deixaram de cumprir a medida, já entre os adolescentes do sexo masculino foram $19 \%$ os que não cumpriram a medida determinada pela justiça.

Os dados que constam nos relatórios, prontuários e outros documentos atestam que a maioria dos envolvidos em ato infracional que não cumpriram a medida teve como característica o não comprometimento dos adolescentes e familiares com as ações propostas pela equipe do Programa. Outro fator também detectado foi o fato de adolescentes estarem, na época do cumprimento da medida, seriamente envolvidos (as) com uso e tráfico de drogas, e até mesmo ter reincidido em ato infracional mais grave. Tais procedimentos (dados dos relatórios enviados à Vara da Infância) exigiam novas ações, fazendo com que os/as adolescentes migrassem para a medida de Liberdade Assistida por ordem da justiça, e até por solicitação dos educadores, dada a complexidade dos casos.

Dos prontuários pesquisados $7,7 \%$ das adolescentes do sexo feminino, encontravam-se envolvidas com uso e tráfico de drogas. As informações extraídas da oitiva encaminhada pelo sistema de justiça sugerem que este é um fator desencadeador da prática de ato infracional para ambos os sexos. Entre os adolescentes do sexo masculino, este percentual sobe para $22,8 \%$, o que mostra a disseminação cada vez maior do uso de substâncias psicoativas entre adolescentes. Impressiona também a quantidade de crack disponível no mercado das drogas. Conforme resultado divulgado pelo Relatório Circunstanciado da Diretoria Anti Drogas do município de Maringá, em 2009, foram apreendidas 55.530,20 gramas de crack no município. 
Tabela 5 - Distribuição dos adolescentes por ano de nascimento e ato infracional no município de Maringá em 2009 (feminino)

\begin{tabular}{|c|c|c|c|c|c|c|c|c|c|c|c|c|}
\hline Ato & \multicolumn{2}{|c|}{ Tráfico } & \multicolumn{2}{|c|}{ Briga } & \multicolumn{2}{|c|}{ Roubo/furto } & \multicolumn{2}{|c|}{ D.S.H } & \multicolumn{2}{|c|}{ Outros } & \multicolumn{2}{|c|}{ Total } \\
\hline $\begin{array}{c}\text { Ano de } \\
\text { nascimento }\end{array}$ & C & N.C & C & N.C & C & N.C & C & N.C & C & N.C & C & N.C \\
\hline 1991 & - & - & 01 & & 02 & - & 01 & - & - & - & 04 & 01 \\
\hline 1992 & - & - & 04 & - & 01 & - & - & - & - & - & 05 & - \\
\hline 1993 & 02 & - & 02 & - & - & - & - & - & - & - & 04 & - \\
\hline 1994 & - & - & 02 & - & 04 & - & - & - & - & - & 06 & - \\
\hline 1995 & - & - & 04 & - & 01 & - & - & - & 01 & - & 06 & - \\
\hline 1997 & - & - & - & - & 01 & - & - & - & - & - & 01 & - \\
\hline Total & 02 & - & 13 & 01 & 09 & - & 01 & - & 01 & - & 26 & 01 \\
\hline
\end{tabular}

${ }^{*}$ C - cumpriu / N.C - não cumpriu - D.S.H (dirigir sem habilitação) - Pesquisa realizada no período de jul. a nov. de 2010 no CRSE.

Fonte: os autores a partir do registro dos profissionais do CRSE: pesquisa realizada no período de jul. a nov. de 2010 no CRSE.

Com relação ao ato infracional a variável briga se destaca com mais de $50 \%$ das adolescentes do sexo feminino, e a variável roubo foi 0 ato praticado por aproximadamente $33 \%$ das adolescentes. Dados dos prontuários demonstram que a maioria das adolescentes com idade entre 14 e 15 anos estavam envolvidas em brigas, chegando "às vias de fato", ou seja, entrando em luta corporal por motivos relacionados a namoro e até mesmo a perda do namorado para outras adolescentes.

Tabela 6 - Distribuição dos adolescentes por ano de nascimento e ato infracional no município de Maringá em 2009 (masculino)

\begin{tabular}{c|cc|cc|cc|cc|cc|cc}
\hline & \multicolumn{2}{|c|}{ Tráfico } & \multicolumn{2}{c|}{ Briga } & \multicolumn{2}{|c|}{ Roubo/furto } & \multicolumn{2}{c|}{ D.S.H } & \multicolumn{2}{c|}{ Outros } & \multicolumn{2}{c}{ Total } \\
\hline & C & N.C & C & N.C & C & N.C & C & N.C & C & N.C & C & N.C \\
1991 & 09 & 09 & 04 & 02 & 03 & 02 & 08 & 04 & 03 & 03 & 27 & 20 \\
1992 & 04 & - & 10 & 01 & 12 & 03 & 05 & - & 04 & 01 & 35 & 05 \\
1993 & 07 & - & 14 & - & 08 & 01 & 01 & - & 06 & - & 36 & 01 \\
1994 & 04 & - & 04 & - & 08 & 02 & - & - & - & - & 16 & 02 \\
1995 & 02 & - & 03 & - & 01 & - & - & - & 02 & 01 & 08 & 01 \\
1996 & - & - & 02 & - & - & - & - & - & - & - & 02 & - \\
\hline Total & 26 & 09 & 37 & 03 & 32 & 08 & 14 & 04 & 15 & 05 & $\mathbf{1 2 4}$ & $\mathbf{2 9}$ \\
\hline
\end{tabular}

${ }^{*} \mathrm{C}$ - cumpriu / N.C - não cumpriu - D.S.H-dirigir sem habilitação - Pesquisa realizada no período de jul. a nov. de 2010 no CRSE.

Fonte: os autores a partir do registro dos profissionais do CRSE: pesquisa realizada no período de jul. a nov. de 2010 no CRSE.

Com relação ao ato infracional praticado, entre os adolescentes do sexo masculino a variável briga chegou a $26 \%$, seguido da variável tráfico, que chega a $23 \%$ percentual correspondente também a variável roubo. Os adolescentes autores dos atos infracionais citados encontravam-se, na época da pesquisa, em sua maioria com 17 anos de idade. 0 comprometimento dos adolescentes com as substâncias psicoativas se deu inicialmente 
por meio do uso, cuja necessidade de obter a droga pode levar ao tráfico. Tal informação foi comprovada por meio dos dados analisados nos prontuários consultados, bem como pode ser visto na bibliografia estudada.

É bastante comum, hoje em dia, verificar-se jovens viciados ${ }^{7}$ em entorpecentes trabalhar para o tráfico em troca de pequenas quantidades de droga para consumo próprio; isto representa no tráfico um ganho pecuniário muito alto, pois se passa a lidar com uma marionete que aceita tudo e tudo faz em troca de quase nada (PRATES, 2010, p. 69).

Nota-se, portanto, as situações de risco pessoal e social que abarcam a vida do adolescente, visto que eles inserem-se na rede organizada do crime, muitas vezes, colocando em risco suas vidas para a obtenção de dinheiro e droga. Fato este que se expressa no uso de substância psicoativa, e, em decorrência disso, a prática de ato infracional. Este fato nos leva a refletir sobre a importância da aplicação das medidas protetivas e socioeducativas previstas no ECA, art. 112, bem como um trabalho articulado das redes de atendimento e proteção visando a superação de tais situações.

Analisando os dados da pesquisa, concluímos que a construção do perfil demanda a análise de vários dos fatores que caracterizam o modo como vivem os adolescentes que cumprem a medida socioeducativa de Prestação de Serviços à Comunidade, e tiveram passagem pelo CRSE em 2009. Dos 180 prontuários pesquisados, 27 são de adolescentes do sexo feminino, o maior número delas recebeu medida por briga, ou teve participação em algum caso de agressão a outras adolescentes. Na escola, estão no sistema regular, cursando o ensino fundamental, moram somente com a mãe, com maior concentração nos bairros Requião e Jardim Alvorada, e o ato infracional ocorreu quando tinham entre 14 e 17 anos de idade.

Com relação aos adolescentes do sexo masculino, observamos que no universo de 153 a maioria recebeu a medida por briga, chegando "as vias de fatos", tráfico e uso de drogas. No momento do cumprimento da medida estavam cursando o ensino fundamental na modalidade supletivo, sistema CEEBEJA, moravam com pai e mãe, e cometeram ato infracional entre 15 e 17 anos de idade.

\footnotetext{
7 A fidelidade em relação à citação nos leva a manter o termo viciado contido na frase como originariamente utilizado pelo autor.
} 
A pesquisa apresentou dados que definem os bairros Requião e Alvorada como local do maior número de adolescentes autores de ato infracional. No bairro Requião, por meio de leitura dos prontuários, observa-se que há uma grande concentração de famílias de baixo poder aquisitivo. É também um bairro afastado da região central da cidade, e com poucas oportunidades de emprego, o que obriga a população em atividade no mercado de trabalho a se deslocar para outras regiões, permanecendo por muito tempo longe de seus lares e consequentemente de seus filhos.

O Jardim Alvorada possui características diferentes, o bairro sofreu mudanças com o passar dos anos (crescimento desordenado), constituindo-se em um bairro "de vida própria", ou seja, mantém os serviços públicos básicos, comércio próprio, mas, no que se refere aos serviços e bens públicos, tais como segurança, não teve o mesmo desenvolvimento, como também a ausência de políticas sociais específicas para as demandas locais.

\section{Conclusão}

Ao finalizar a construção deste trabalho, constatamos que o tratamento dispensado a assistência à criança e ao adolescente no Brasil foi sempre determinado pelo poder econômico, que buscava estabelecer parâmetros de atendimento conforme a necessidade do setor produtivo.

A busca por mecanismos que possam atender às necessidades da criança e do adolescente esbarra na ideologia de domínio sobre os pobres. O Estado passa a criar instituições com nomenclaturas diferentes, mas com os mesmos objetivos, afastar a criança e o adolescente do seio da família em nome da segurança.

A mobilização de vários segmentos da sociedade na década de 1980 procurava introduzir na Constituição Federal de 1988 os direitos da criança e do adolescente, foi um marco histórico que culminou com a aprovação do Estatuto da Criança e do Adolescente, Lei 8.069/1990. A nova Lei superou os Códigos anteriores que camuflavam visões distorcidas sobre a condição da infância e da juventude em nome de direitos, e passou a considerar a criança e o adolescente como sujeito de direitos, pelo princípio da absoluta prioridade no seu atendimento e pela observância de sua condição peculiar de pessoa em desenvolvimento. 
O Art. 112 do ECA estabelece medidas socioeducativas para o adolescente autor de ato infracional. Em nosso trabalho, observamos que a maioria dos adolescentes encaminhados pela justiça, para o cumprimento da medida socioeducativa de Prestação de Serviços à Comunidade em 2009, no município de Maringá-PR, cumpriu a medida. Este fato significa que os objetivos foram alcançados, ou seja, foi dado ao adolescente a oportunidade de reconhecer e rever sua conduta e refletir sobre o seu papel na sociedade.

Entendemos que o momento requer estudo mais aprofundado em relação à execução da medida. A nosso ver, a medida de Prestação de Serviços à Comunidade é um instrumento de aproximação do adolescente com a sociedade e, se bem executada, pode ser uma ferramenta para que o adolescente rompa com a prática de atos infracionais, bem como com o agravamento dos delitos cometidos e consequentemente a sua migração, para a medida de Liberdade Assistida e até mesmo para internação.

\section{Referências}

ALVES, G. Dimensões da globalização: o capital e suas contradições. Londrina: Práxis, 2001.

ARANTES, E. M. de M. Rostos de crianças no Brasil. In: RIZZINI, Irene; PILOTTI Francisco (Org.). Arte de governar crianças: a história das políticas sociais, da legislação e da assistência à infância no Brasil. 2. ed. São Paulo: Cortez, 2009. p. 153-201.

BRASIL. Constituição da República Federativa do Brasil, de 5 de outubro de 1988. 44. ed. São Paulo: Saraiva, 2010.

BRASIL. Lei no 8.069 de 13 de julho de 1990. Dispõe sobre o Estatuto da Criança e do Adolescente, e dá outras providencias. Brasília, 1990.

FALEIROS, V. de P. Infância e processo político no Brasil. In: RIZZINI, Irene; PILOTTI Francisco (Org.). A arte de governar crianças: a história das políticas sociais, da legislação e da assistência à infância no Brasil. Santa Úrsula: Amais, 1995. p. 47-98.

GONÇALVES, L. L. A vez e a voz de adolescente em PSC na UFRGS: ato infracional e educação. 2002. Dissertação (Mestrado em Educação) - Universidade Federal do Rio Grande do Sul, Porto Alegre.

LIBERATI, W. D. Comentários ao estatuto da criança e do adolescente. 11. ed. São Paulo: Malheiros, 2010. 
MARINGÁ. Prefeitura Municipal. Lei n.o 2773 de 27 de novembro de 1990. Dispõe sobre a Política Municipal de Atendimento dos Direitos da Criança e do Adolescente e dá outras providências.

PATOLOGIA SOCIAL. In: Infopédia. Porto: Porto, 2003. Disponível em: <http://www.infopedia.pt/\$patologia-social>. Acesso em: 30 nov. 2010.

PRATES, F. C. Adolescente infrator: a prestação de serviços à comunidade. 11. ed. São Paulo: Juruá, 2010.

RIZZINI, I. Crianças e menores: do pátrio poder ao pátrio dever: um histórico da legislação para a infância no Brasil. In: RIZZINI, I.; PILOTTI Francisco (Org.). A arte de governar crianças: a história das políticas sociais, da legislação e da assistência à infância no Brasil. 2. ed. São Paulo: Cortez, 2009. p. 97-149.

RIZZINI, I. O Século perdido: raízes históricas das Políticas Públicas para a Infância no Brasil. 2. ed. São Paulo: Cortez, 2008.

RIZZINI, I.; PILOTTI, Francisco (Org.). A arte de governar crianças: a história das políticas sociais, da legislação e da assistência à infância no Brasil. 2. ed. São Paulo: Cortez, 2009.

SARAIVA, João Batista Costa. Medidas socioeducativas e o adolescente autor de ato infracional. Disponível em: <http://jusvi.com/artigos/38831/2> Acesso em: 30 nov. 2010.

SOARES, Janine Borges. A construção da responsabilidade penal do adolescente no Brasil: uma breve reflexão histórica. Disponível em:

<http:/www.mp.rs.gov.br/infância/doutrina/id186.htm>. Acesso em: 19 jul. 2010.

VOLPI, Mario. (Org.). Adolescentes privados de liberdade: a normativa nacional e internacional e reflexões acerca da responsabilidade penal. 4. ed. São Paulo: Cortez, 2008.

VOLPI, Mario. Sem liberdade, sem direitos: a privação de liberdade na percepção do adolescente. 4. ed. São Paulo: Cortez, 2001. 